\title{
The Planet-B neutral gas mass spectrometer
}

\author{
H. B. Niemann ${ }^{1}$, D. N. Harpold ${ }^{1}$, S. Feng ${ }^{1}$, W. T. Kasprzak ${ }^{1}$, S. H. Way ${ }^{1}$, S. K. Atreya ${ }^{2}$, B. Block ${ }^{2}$, G. R. Carignan ${ }^{2}$, \\ T. M. Donahue ${ }^{2}$, A. F. Nagy², S. W. Bougher ${ }^{3}$, D. M. Hunten ${ }^{3}$, T. C. Owen ${ }^{4}$, S. J. Bauer ${ }^{5}$, H. J. Hayakawa ${ }^{6}$, \\ T. Mukai ${ }^{6}$, Y. N. Miura ${ }^{7}$, and N. Sugiura ${ }^{7}$ \\ ${ }^{1}$ Goddard Space Flight Center, U.S.A. \\ ${ }^{2}$ Department of Atmospheric, Oceanic and Space Sciences, University of Michigan, U.S.A. \\ ${ }^{3}$ Lunar and Planetary Laboratory, University of Arizona, U.S.A. \\ ${ }^{4}$ University of Hawaii, Institute for Astronomy, U.S.A. \\ ${ }^{5}$ University of Graz, Austria \\ ${ }^{6}$ Institute of Space and Astronautical Science, Japan \\ ${ }^{7}$ University of Tokyo, Japan
}

(Received October 31, 1997; Revised April 9, 1998; Accepted June 4, 1998)

\begin{abstract}
The Planet-B neutral gas mass spectrometer is designed for in-situ measurements of the gas composition in the upper atmosphere of Mars. The sensor uses a dual frequency quadrupole mass analyzer with a mass range of 1$60 \mathrm{amu}$ (atomic mass units) and two electron multipliers to cover the dynamic range required. The ion source, which is collinear with the analyzer, operates in two different modes: 1) a closed source mode measuring non-surface reactive neutral species that have thermally accommodated to the gas inlet walls; and 2) an open source mode measuring chemically surface active species by direct beaming with no surface collisions. The in-line Retarding Potential Analysis (RPA) system selects the mode of operation. An onboard Field Programmable Gate Array (FPGA) is used to control the instrument operating parameters in accordance with pre-programmed sequences and to package the telemetry data. The sensor is sealed and maintained in a vacuum prior to launch and will be opened to the environment of Mars after orbit insertion. Measurements of $\mathrm{He}, \mathrm{N}, \mathrm{O}, \mathrm{CO}, \mathrm{N}_{2}, \mathrm{NO}, \mathrm{O}_{2}, \mathrm{Ar}$, and $\mathrm{CO}_{2}$ will be done at periapsis and the data will be used to determine the variation of the neutral atmosphere density and temperature with altitude, local solar time and season. Measurements are possible from 130-140 km to $500 \mathrm{~km}$ depending on the gas species, chemical background, and instrument measurement mode. The data will contribute to the studies of thermosphere energetics, lower atmosphere meteorology (e.g. dust storms) and serve as a resource for studies of the interaction of the upper atmosphere with the solar wind.
\end{abstract}

\section{Introduction}

The Planet-B mission to Mars will study the upper atmosphere and its interaction with the solar wind. The ion and electron environment will be measured by at least 6 instruments; the neutral atmosphere will be measured in-situ by the Neutral gas Mass Spectrometer (NMS) and remotely by the Ultra Violet Spectrometer (UVS). The NMS instrument observation objective is:

- The in-situ measurement of the neutral composition, isotopic ratios and temperature of the major gas species ( $\mathrm{He}, \mathrm{N}, \mathrm{O}, \mathrm{CO}, \mathrm{N}_{2}, \mathrm{NO}, \mathrm{O}_{2}, \mathrm{Ar}$, and $\mathrm{CO}_{2}$ ) in the Martian upper atmosphere using a quadrupole mass spectrometer.

The science objectives are:

- To determine the variation of the neutral composition with altitude, local solar time, season and solar activity

- To study thermospheric energetics, transport, and circulation; evolution of the atmosphere; and the formation of the ionosphere

Copy right(C) The Society of Geomagnetism and Earth, Planetary and Space Sciences (SGEPSS); The Seismological Society of Japan; The Volcanological Society of Japan; The Geodetic Society of Japan; The Japanese Society for Planetary Sciences.
- To study the effects of lower atmosphere dust storms on the composition, temperature and dynamics of the upper atmosphere

- To provide a Planet-B resource for studies involving the neutral upper atmosphere, ionosphere and solar wind interaction.

Previous in-situ neutral upper atmosphere measurements come from the Viking pre-entry neutral mass spectrometer (Nier and McElroy, 1977) at solar minimum when Mars was near aphelion. The dayside measurements were made at approximately $44^{\circ}$ solar zenith angle. In the altitude range 120-200 km, $\mathrm{CO}_{2}, \mathrm{~N}_{2}, \mathrm{CO}, \mathrm{O}_{2}, \mathrm{NO}$ and $\mathrm{Ar}$ (Nier and McElroy, 1977) were measured and $\mathrm{O}$ was inferred by modeling (Hanson et al., 1977). Isotopic ratios of ${ }^{13} \mathrm{C} /{ }^{12} \mathrm{C},{ }^{18} \mathrm{O} /{ }^{16} \mathrm{O}$ and ${ }^{15} \mathrm{~N} /{ }^{14} \mathrm{~N}$ were determined near the homopause level at approximately $120 \mathrm{~km}$. Wave-like structures were observed in the derived scale height temperatures. More recently, near solar minimum, the Mars Pathfinder descent provided mass densities and inferred temperatures up to about $120 \mathrm{~km}$ near local solar time 3-4 am. Helium has been detected by remote sensing (Krasnopolsky et al., 1994). Figure 1 shows the Mars' upper atmosphere dayside composition for low solar activity as measured during the Viking pre-entry science phase (Nier and McElroy, 1977); a model of O (Hanson et 


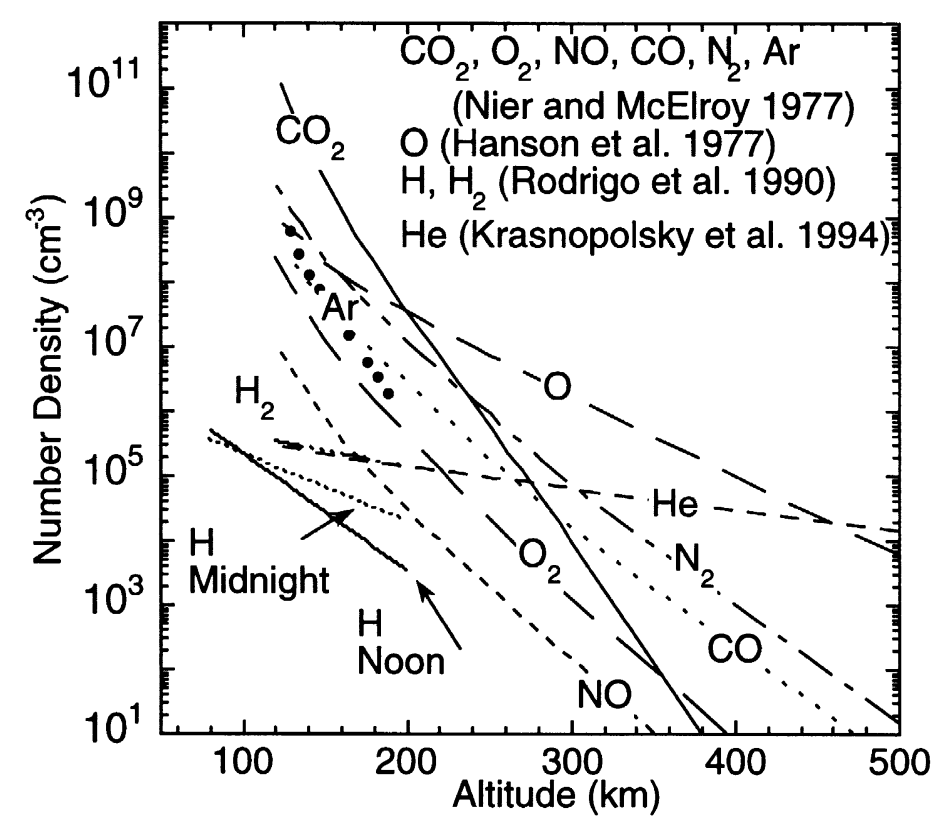

Fig. 1. Composition of the dayside Mars thermosphere at low solar activity with Mars near aphelion as derived from in-situ measurements by the Viking 1 pre-entry science mass spectrometer for $\mathrm{CO}_{2}, \mathrm{NO}, \mathrm{CO}, \mathrm{N}_{2}, \mathrm{O}_{2}$, and $\mathrm{Ar}$ (Nier and McElroy, 1977), O as modeled by Hanson et al. (1977), $\mathrm{H} 2$ and $\mathrm{H}$ from a chemical model (Rodrigo et al., 1990), and He estimated from a recent remote sensing measurement (Krasnopolsky et al., 1994). The Planet-B mission is expected to occur during high solar activity with higher densities and temperatures.

al., 1977); a model of $\mathrm{H}$ and $\mathrm{H}_{2}$ (Rodrigo et al., 1990); and He extrapolated from a measurement of the mixing ratio in the lower atmosphere (Krasnopolsky et al., 1994).

The eccentric orbit of Mars makes the solar radiation stronger at perihelion than at aphelion and there are strong seasonal variations. The combined effects of radiation at perihelion plus topography trigger global dust storms which heat the upper stratosphere. Such effects were observed to inflate the entire atmosphere at the time of arrival of Mariner 9 , raising the altitude of constant density surfaces. This dust storm coupling of the Mars upper and lower atmospheres has important implications for the orbit insertion of future Mars-bound spacecraft. Dust storm events and their impacts on the Mars upper atmosphere were recently simulated and studied in preparation for Mars Global Surveyor aerobraking activities (Bougher et al., 1997). Global pressure changes are observed in the lower atmosphere as a function of season due to the sublimation of $\mathrm{CO}_{2}$ at the poles. The upper atmosphere is significantly affected by the solar EUV and global circulation (Bougher et al., 1990). Mean dayside temperatures from neutral density scale heights, plasma scale heights and airglow intensity scale heights range from about $130 \mathrm{~K}$ to $350 \mathrm{~K}$ for solar activity levels corresponding to $F_{10.7}$ values extrapolated to Mars' orbit from 25-85 $\left(\times 10^{-22} \mathrm{Wm}^{-2} \mathrm{~Hz}^{-1}\right)$ (Bougher et al., 1990). Estimated day-to-night temperature differences range from $45 \mathrm{~K}$ at low solar activity (Viking) to $130 \mathrm{~K}$ at high solar activity (Mariner 6, 7) (Bougher et al., 1990). Solar activity for the Planet-B mission is expected to be near solar maximum (Schatten and Pesnell, 1993; Joselyn et al., 1977) with correspondingly higher densities and temperatures than the solar minimum Viking data. Figure 2 shows the expected diurnal variation of the exospheric temperature during several missions to Mars at different levels of solar activity (Bougher and Shinagawa, 1998; Bougher et al., 1990).

Although Mars has a much less massive atmosphere than Venus, the density of the neutral atmosphere in the region from $250 \mathrm{~km}$ to $450 \mathrm{~km}$ is of the same order of magnitude. Hot $\mathrm{O}$ and $\mathrm{H}$ (Nagy et al., 1990) are expected to be present in low concentrations at high altitudes. Atomic nitrogen could be present in the Mars upper atmosphere as it is on Venus (Kasprzak et al., 1980). However, the NMS measurement technique for $\mathrm{N}$ (and $\mathrm{O}$ ) will be different from that of the Pioneer Venus Mission (Niemann et al., 1980b) because of the presence of $\mathrm{NO}$ (and $\mathrm{O}_{2}$ ) in Mars' upper atmosphere. Super-rotation of the thermosphere is known to exist for Earth, Venus and some of the outer planets, and presumably exists for Mars. For Venus it was determined from measurements of thermosphere He and H (e.g. Mayr et al., 1980). Wave-like perturbations are observed in the Venus thermosphere (Kasprzak et al., 1988, 1993a) which have been shown to be due to upward propagating gravity waves and similar techniques can be used to deduce the properties of wave structures in the Mars thermosphere. For Venus, gravity waves and super-rotation of the thermosphere combine to produce large dawn-dusk asymmetries in the diurnal variation of the neutral and ion composition. Similar dynamic asymmetries can be expected for Mars.

Measurements of $\mathrm{H}, \mathrm{D}$ and $\mathrm{H}_{2}$ by the UVS will give important information on escape of these gases (reviewed by Hunten, 1993). Using ionosphere and neutral atmosphere data it is possible to compute the in-situ $\mathrm{D} / \mathrm{H}$ ratio in the upper atmosphere if the conditions for charge exchange equilibrium are valid (Grebowsky et al., 1995). NMS measurements of $\mathrm{H}$ and $\mathrm{H}_{2}$ are expected to be marginal because of the sizable gas background expected from surface outgassing of 


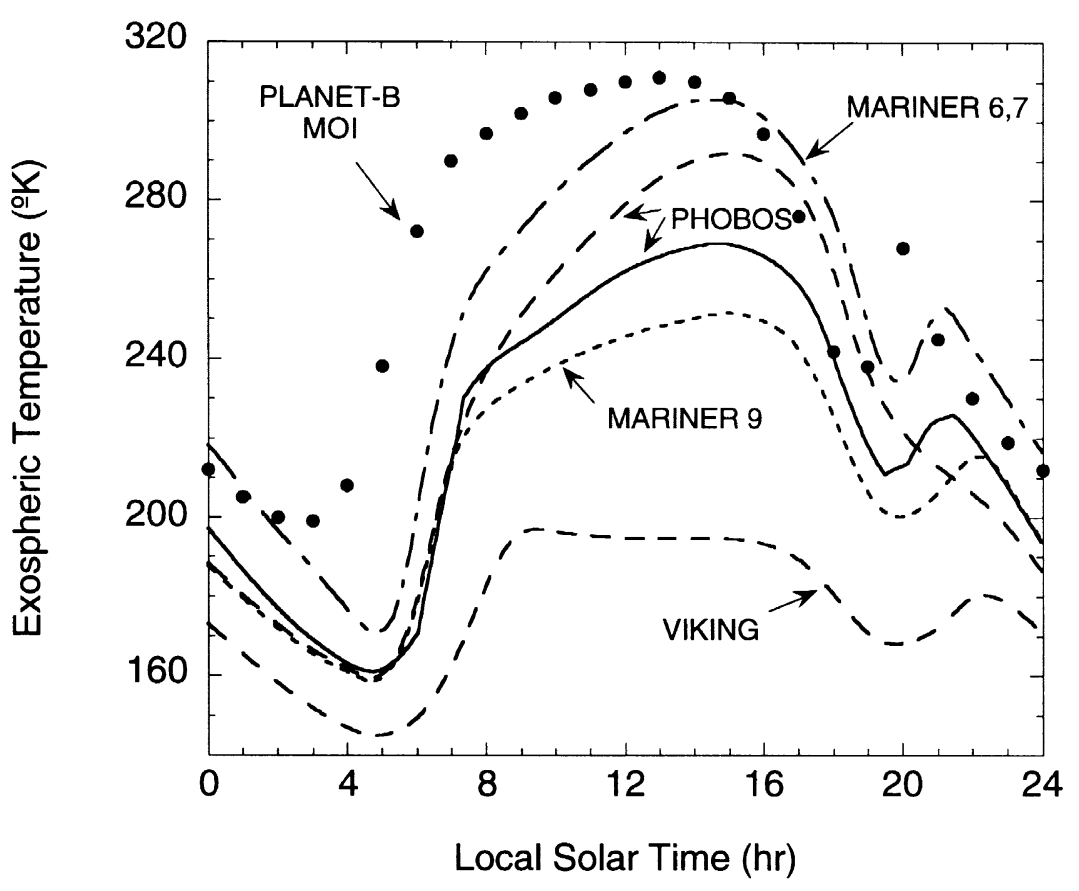

Fig. 2. Prediction of Mars' diurnal variation of the exospheric temperature (Bougher et al., 1990) for the Viking pre-entry science $\left(\mathrm{F}_{10.7}=68\right)$, the Mariner 9 mission $\left(\mathrm{F}_{10.7}=112\right)$, Phobos mission $\left(\mathrm{F}_{10.7}=150\right)$, and the Mariner 6, 7 mission $\left(\mathrm{F}_{10.7}=206\right)$. The Planet-B mission model prediction is for October 1999 and $F_{10.7}=200$ (Bougher and Shinagawa, 1998).

$\mathrm{H}_{2}$ compared to the ambient signal level. Actual orbit measurements will be needed to fully evaluate the potential for measuring these species. Neutral atmosphere measurements are possible in the Martian dust rings and near the satellites using extended integration periods for the expected neutral species and for the signal background.

Isotopic ratios are of great interest as clues to atmospheric origin and evolution. However, the NMS ratio measurements will be in a region of the thermosphere that is diffusively separated. Extrapolation to a lower atmosphere mixing ratio requires an accurate knowledge of the homopause altitude. To determine the homopause altitude the measured $\mathrm{N}_{2} / \mathrm{CO}_{2}$ ratio will be compared with the known value for the mixed atmosphere.

As the Planet-B spacecraft passes through periapsis, it carries out an altitude scan at one local solar time over a latitude band centered very near the equator. The Martian local time of this scan goes through an entire diurnal cycle in one Martian year, or 687 Earth days. This diurnal scan is a seasonal one and an annual one with exactly the same periods, though seasonal effects should be small at the low latitudes covered. As shown by Mariner 6, 7, and 9 (Stewart, 1972), the UVS instrument has the capability to measure certain atmospheric constituents at latitudes and local times other than those at periapsis so that the two instrument measurements are complementary. Measurements by the NMS down to $140 \mathrm{~km}$ or lower are possible. The upper altitude limit for the closed source is species dependent. For non-surface reactive gases (e.g. He, $\mathrm{CO}_{2}$ ) it is limited by the signal statistics. For reactive gases (e.g. $\mathrm{O}$ and $\mathrm{N}$ ) it is influenced by the slowly desorbing gases from the surfaces which were collected during the prior periapsis pass (Niemann et al., 1980b). The open source detection threshold is limited by signal statistics only.

Densities of each constituent, and temperature profiles derived from their scale heights, will be a basic resource for the other experiments on the spacecraft. This resource will typically be used in two ways: orbit-by-orbit comparisons, and comparison with a global model of densities and temperatures. The global model will be an input to physical models of the heat balance and general circulation (Bougher et al., 1990), and will provide an input to aeronomical models treating photochemistry, transport, and recombination. NMS data coupled with the Mars TGCM (Thermosphere General Circulation Model), complementary Mars '98 Pressure Modulated InfraRed Radiometer (PMIRR) data and the altitude of the ionospheric peak will provide a monitor of lower atmospheric perturbations, such as dust storms. The Mars TGCM will serve as a theoretical link (from 70 to $150 \mathrm{~km}$ ) between the PMIRR and the NMS data.

The neutral gas density measurements will be an input to ionosphere models. The ionosphere is formed from the neutral atmosphere and electrons produced by photoionization of the neutral species contribute to the electron population. Ionneutral collisions affect ionospheric drift and the propagation of plasma waves. The ionosphere, plus any remnant magnetic field, form the obstacle to the solar wind. The NMS data in the exosphere will provide inputs for ion pickup calculations. Classical $\mathrm{O}^{+}$pickup ions are formed from ionization of exospheric $\mathrm{O}$ atoms which are swept away by the solar wind. The behavior of the exobase oxygen is determined by the neutral thermosphere structure and dynamics (e.g. Nagy et al., 1990). The solar wind motional electric field that maps down into the magnetosphere and ionosphere can accelerate 


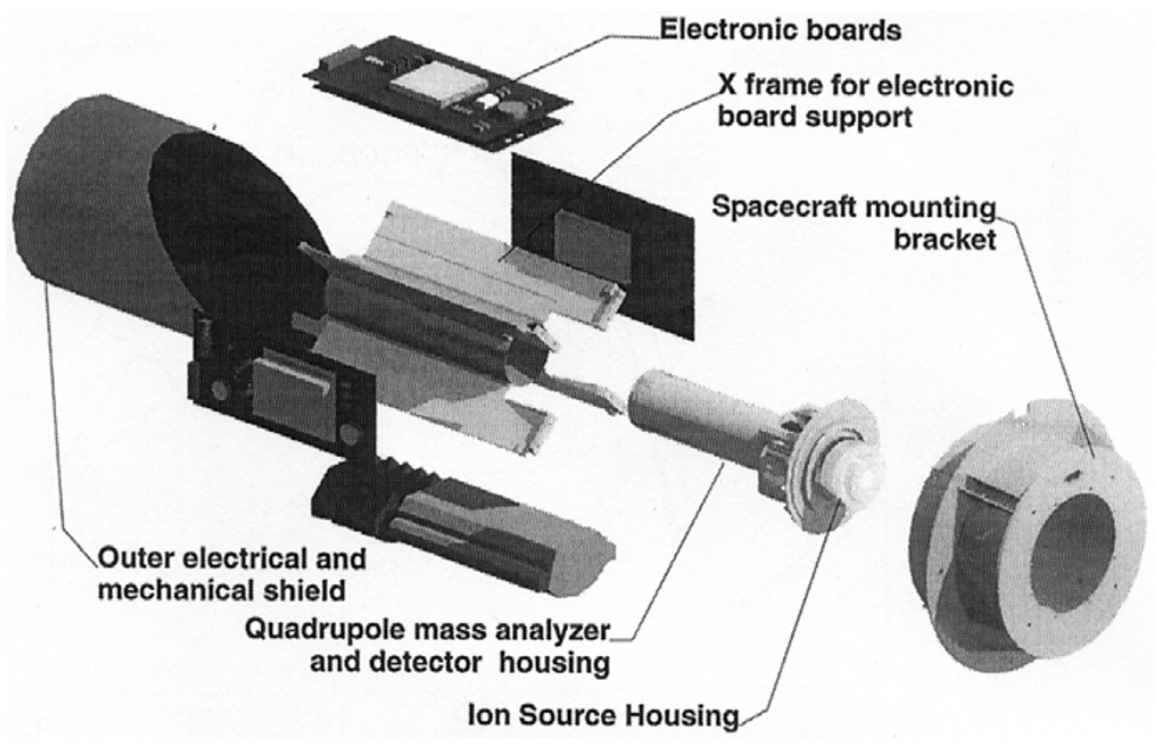

Fig. 3. The mechanical elements of the NMS.

ionospheric ions as for Venus (e.g. Luhmann et al., 1995). The escaping energetic ions represent a neutral atmosphere loss for Mars (e.g. Lundin et al., 1989).

\section{NMS Instrument and Operation}

The NMS is a modification of the instrument used on the Pioneer Venus Orbiter (ONMS) (Niemann et al., 1980a) to determine the neutral gas composition and temperature in the Venus thermosphere and exosphere (Niemann et al., 1980b). The ONMS operated for nearly 14 years in the Venus environment including the final pre-entry phase (Kasprzak et al., 1993a,b). The NMS sensor uses a dual frequency quadrupole mass analyzer with a mass range of 1-60 amu (atomic mass units) and two secondary electron multipliers to cover the dynamic range required. The ion source, which is collinear with the analyzer, operates in two different modes: 1) a closed source mode measuring non-surface reactive neutral species that have thermally accommodated to the gas inlet walls; and 2) an open source mode measuring direct beaming, chemically surface active, species coming in at spacecraft equivalent energies. An in-line Retarding Potential Analysis (RPA) system selects the operational mode. In the closed source mode there is an additional ram pressure enhancement when the orifice is pointed in the direction of the spacecraft motion which lowers the detection threshold. The NMS instrument sensitivity has been increased by about a factor of 6 relative to that of the Pioneer Venus instrument to compensate for the decreased $\mathrm{O}$ concentration of Mars relative to that of Venus. A summary of the pertinent NMS instrument parameters is given in Table 1.

The NMS sensor and electronics package is cylindrical in shape with the entrance aperture of the sensor at one end of the cylinder. The entrance aperture is covered by a metalceramic breakoff hat that is pyrotechnically removed after orbit insertion. The instrument is mounted on the same spacecraft panel as the extendable magnetometer MaST (MST).
The normal to the sensor aperture is normal to the spacecraft panel. The electronics are mounted in an " $X$ " shaped frame which surrounds the cylindrical sensor housing at its center (Fig. 3). The outer cylindrical shell serves as mechanical and electrical shield. The sensor cross-section (Fig. 4) shows the ion source with the break off hat removed, the quadrupole analyzer and the secondary electron multiplier detectors. A getter pump is used to maintain vacuum in the sensor prior to opening it to the Martian atmosphere. Once opened to the atmosphere, the analyzer volume, which is isolated from the ion source region, is vented in a direction that is at right angles to that of the ion source ram direction. This keeps the analyzer pressure lower than the ambient ram pressure and ion-molecule scattering effects in the analyzer are minimized or nonexistent.

The principal components of the mass spectrometer are: (1) the ion source, (2) a high resolution quadrupole mass filter, and (3) two secondary electron multiplier detectors. The electron gun uses a heated filament to supply the electrons needed for gas ionization. The quadrupole mass filter consists of four precision ground hyperbolic rods mounted in a mechanical assembly. An AC and a DC potential is applied to the quadrupole rods creating a dynamic electrostatic field within the quadrupole region that controls the transmitted mass/charge value, the resolution, and the transmission efficiency. The flat-topped mass peaks allow a mass scan mode in which each mass is monitored by a single step to achieve the lowest detection limit in a specified sampling period. A radio frequency $(\mathrm{RF})$ generator drives the quadrupole at two frequencies to reduce the requirements for a large amplitude voltage change imposed by the mass range (1 to $60 \mathrm{amu}$ ). Ions exiting the analyzer are detected by two secondary electron multipliers differing in sensitivity by a factor of about two thousand. Charge pulses at the anode of the multiplier are amplified and counted if they are above a preset discriminator threshold. The lowest count rate detectable is limited by 
Table 1. Listing of NMS instrument parameters.

\begin{tabular}{|c|c|c|}
\hline \multicolumn{3}{|c|}{ Neutral Mass Spectrometer (NMS) instrument parameter table } \\
\hline \multirow[t]{3}{*}{ Gas sampling system } & \multicolumn{2}{|l|}{ 1) Closed source } \\
\hline & \multirow{2}{*}{\multicolumn{2}{|c|}{$\begin{array}{l}\text { 2) Open source (molecular beaming) with retarding potential } \\
\text { analyzer (RPA) energy discrimination }\end{array}$}} \\
\hline & & \\
\hline \multirow[t]{2}{*}{ Ion source } & \multirow{2}{*}{\multicolumn{2}{|c|}{$\begin{array}{l}\text { Electron impact ionization; electron energies } 75 \text { and } 25 \mathrm{eV} \text {; in-line } \\
\text { particle retarding }\end{array}$}} \\
\hline & & \\
\hline Sensitivity & \multicolumn{2}{|c|}{$1 \times 10^{-4}($ counts $/ \mathrm{sec}) /\left(\right.$ part $\left./ \mathrm{cm}^{3}\right)$} \\
\hline \multirow[t]{4}{*}{ Density range } & \multicolumn{2}{|c|}{ 1) Ion source density about $170 \mathrm{~cm}^{-3}($ signal/noise ratio $=1)$ to } \\
\hline & \multicolumn{2}{|c|}{$10^{12} \mathrm{~cm}^{-3}$ (max. ion source pressure $10^{-4} \mathrm{mbar}$ ); 2) Ambient density } \\
\hline & \multicolumn{2}{|c|}{$2 \times 10^{4} \mathrm{~cm}^{-3}$ to $10^{12} \mathrm{~cm}^{-3}$ (integration period $=0.011 \mathrm{sec}$ ) } \\
\hline & \multicolumn{2}{|c|}{ Ram pressure enhancement $=46.9$ for $\mathrm{CO}_{2}$ at $4.44 \mathrm{~km} / \mathrm{sec}$} \\
\hline \multirow[t]{2}{*}{ Mass analyzer } & \multicolumn{2}{|c|}{ Quadrupole mass filter, $0.2 \mathrm{~cm}$ field radius, $7.5 \mathrm{~cm}$ rod length } \\
\hline & \multicolumn{2}{|c|}{ Radio frequencies: $3.25 \mathrm{MHz}$ and $4.85 \mathrm{MHz}$} \\
\hline Mass range & \multicolumn{2}{|l|}{$1-60 \mathrm{amu}$} \\
\hline \multirow[t]{2}{*}{ Scan type } & \multirow{2}{*}{\multicolumn{2}{|c|}{$\begin{array}{l}\text { 1) Selected masses for rapid mass sampling; 2) } 1 \text { or } 1 / 8 \text { amu per } \\
\text { step scan from } 1 \text { to } 60 \mathrm{amu} \text {; 3) RPA sweep at fixed mass number }\end{array}$}} \\
\hline & & \\
\hline Resolution/Crosstalk & \multicolumn{2}{|l|}{$<10^{-6}$ for adjacent masses } \\
\hline \multirow[t]{2}{*}{ Ion detector } & \multirow{2}{*}{\multicolumn{2}{|c|}{$\begin{array}{l}\text { Two secondary electron multipliers operating in pulse counting } \\
\text { mode (detector noise } \sim 1 \text { count/minute) }\end{array}$}} \\
\hline & & \\
\hline \multirow[t]{6}{*}{ Sample and integration periods } & Integration & Total sample \\
\hline & Period (ms) & Period (ms) \\
\hline & $64 \mathrm{Kbps}$ & 11.62 \\
\hline & $32 \mathrm{Kbps}$ & 23.24 \\
\hline & $16 \mathrm{Kbps}$ & 46.48 \\
\hline & 1408 & 1487 \\
\hline Spatial resolution & \multicolumn{2}{|c|}{55 meters along spacecraft track for $64 \mathrm{Kbps}$ telemetry rate } \\
\hline Deployment mechanism & \multicolumn{2}{|c|}{ Metal-ceramic breakoff cap, pyrotechnically removed } \\
\hline \multirow[t]{3}{*}{ Viewing angle (angle of response) } & \multicolumn{2}{|c|}{ 1) Closed source, approx. $2 \pi$ steradians } \\
\hline & \multirow{2}{*}{\multicolumn{2}{|c|}{$\begin{array}{l}\text { 2) Open source approx. } 50^{\circ} \text { cone half-angle with respect to normal } \\
\text { of ion source orifice }\end{array}$}} \\
\hline & & \\
\hline \multirow[t]{2}{*}{ Dimensions } & \multirow{2}{*}{\multicolumn{2}{|c|}{$\begin{array}{l}\text { Cylinder } 15.0 \mathrm{~cm} \text { diameter, } 33.7 \mathrm{~cm} \text { length including } 6.95 \mathrm{~cm} \text { for } \\
\text { breakoff cap }\end{array}$}} \\
\hline & & \\
\hline Weight & $2.8 \mathrm{~kg}$ including $0.26 \mathrm{~kg}$ for & ted breakoff cap \\
\hline Power & Average 7.4 watts, peak 11. & tts, standby 6.3 watts \\
\hline Temperature range & $-30^{\circ} \mathrm{C}$ to $+50^{\circ} \mathrm{C}$ operating & \\
\hline & $-40^{\circ} \mathrm{C}$ to $+60^{\circ} \mathrm{C}$ survival & \\
\hline & $-100^{\circ} \mathrm{C}$ to $+200^{\circ} \mathrm{C}$ ion sou & emperature range \\
\hline
\end{tabular}




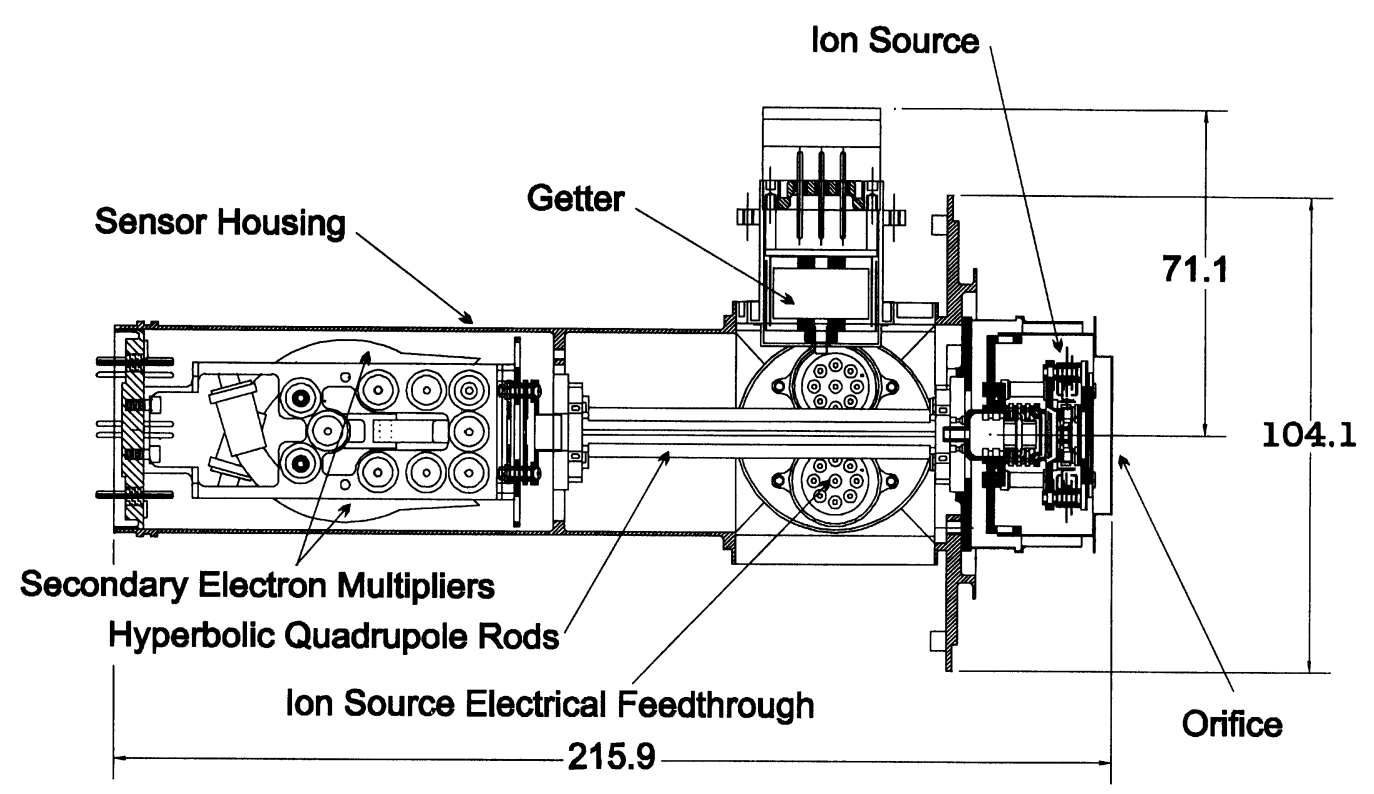

Fig. 4. Outline drawing of the NMS sensor showing the major elements. Dimensions are in mm.

the background noise of the multiplier (approximately one count per minute). The upper count rate is approximately $3 \times 10^{7}$ counts $/$ sec.

A Field Programmable Gate Array (FPGA) is responsible for controlling the various voltages needed by the sensor and for packaging of the detector and associated housekeeping data to be accessed by the spacecraft telemetry bus. The FPGA provides a 9 instruction computer simulation for control and is provided with $8 \mathrm{~K} \times 8$ of RAM and $8 \mathrm{~K} \times 8$ of $\mathrm{PROM}$ memory. The PROM contains a default measurement sequence that can be executed without memory uploads from the spacecraft. Other sequences will require programs to be uploaded to RAM from the spacecraft Backup File Memory (BFM).

The low limit density value in Table 1 cannot always be realized because background gases, identical to those to be measured, are being emitted from the surrounding surfaces or because of interference at some mass numbers of other ambient gases present in high concentrations. The upper density value is limited by molecular mean free path conditions in the ionization and analyzer regions. At high solar activity on the equator this corresponds to an altitude of about $124-128 \mathrm{~km}$ for $\mathrm{CO}_{2}$ (Bougher et al., 1990).

The chemical properties of the species to be measured vary from highly reactive to the nearly inert gases. The nonreactive species $\mathrm{He}, \mathrm{Ar}, \mathrm{CO}, \mathrm{N}_{2}$ and $\mathrm{CO}_{2}$ will be measured in the closed source mode. Some reactive species can be measured in the closed source mode as surface recombined reaction products (i.e. $\mathrm{O}$ as $\mathrm{O}_{2}, \mathrm{~N}$ as $\mathrm{NO}$ ) after the $\mathrm{O}$ surface coverage has reached an equilibrium value. For Pioneer Venus, approximately 15 dayside orbits, ranging in altitude from 150-160 km, were needed to reach O surface equilibrium (Niemann et al., 1980b). At altitudes corresponding to those of Venus, the gas surface equilibration period will be somewhat longer because of the lower $\mathrm{O}$ densities. The species $\mathrm{O}, \mathrm{N}, \mathrm{NO}$ and $\mathrm{O}_{2}$ will normally be measured in the open source mode. At lower altitudes, assuming surface $O$ equilibration has been reached, a switch will be made to the measurement of $\mathrm{O}$ as surface recombined $\mathrm{O}_{2}$ and $\mathrm{N}$ as surface recombined NO.

For the closed source, sensible ambient density measurements can be made from $0^{\circ}$ to about $90^{\circ}$ angle of attack and for the open source from $0^{\circ}$ to about $50^{\circ}$ angle of attack (Niemann et al., 1980a). The angle of attack is the angle between the spacecraft velocity vector and the normal to the NMS orifice. The effective sampling rate will depend on this angle, the spin rate (nominally 8 seconds) and the telemetry bit rate (see Table 1). The current design of the Planet-B orbit for the main mission (Planet-B Interim Report, 1995) has periapsis located near $3^{\circ}$ latitude at an altitude of about $146 \mathrm{~km}$ with apoapsis near $47500 \mathrm{~km}$. The orbit period is 37.9 hours. Due to the exponential decrease of the neutral gas density with increasing altitude, NMS measurements are confined to a region near periapsis. The Planet-B project has defined NMS operations to occur in a 20 minute period centered on periapsis. An altitude of $330 \mathrm{~km}$ (the altitude of the minimum Viking $\mathrm{CO}_{2}$ density (Nier and McElroy, 1977) that would be measured by the NMS) occurs 6 minutes before and after periapsis at latitudes of $21^{\circ}$ and $-15^{\circ}$ respectively ( \pm 10 minutes corresponds to $30^{\circ}$ and $-24^{\circ}$, respectively). The in-situ measurements of the NMS are basically equatorial. Figure 5 illustrates the expected local solar time coverage for the first Martian year of operation. Also, shown for periapsis only, are the maximum angle of attack, the minimum angle of attack, the measurement angle limit of the open source $\left(50^{\circ}\right)$ and the measurement angle limit of the closed source $\left(90^{\circ}\right)$. Closed source measurements at periapsis can be made throughout the first Martian year due to the wide angle of attack response. Similarly, for the open source except at orbit numbers near 180 and in the range $480-550$ where the minimum angle of attack is greater than the nominal operating range. 


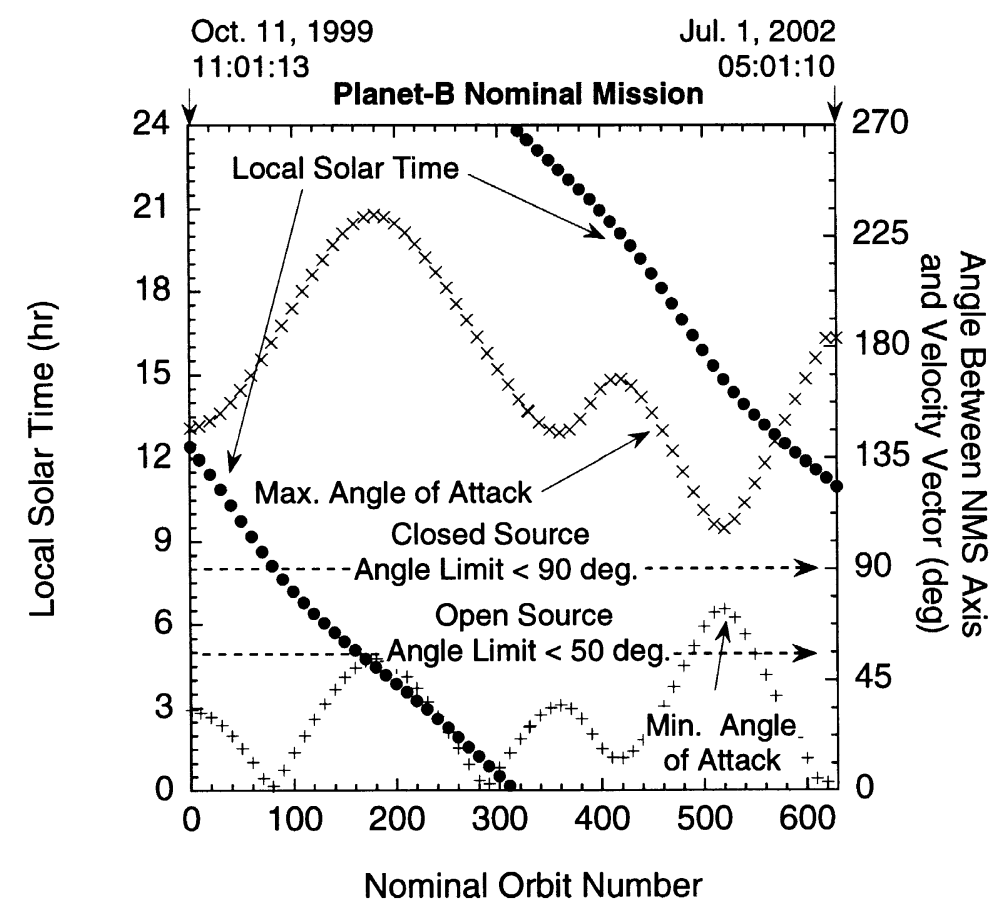

Fig. 5. A plot of the periapsis local solar time, minimum angle of attack and maximum angle of attack as a function of the orbit number. The nominal limits for the angle response of the open and closed source are also shown.

\section{Summary}

The NMS instrument will make in-situ composition measurements of the major neutral gas species in the upper atmosphere of Mars: $\mathrm{He}, \mathrm{N}, \mathrm{O}, \mathrm{CO}, \mathrm{N}_{2}, \mathrm{NO}, \mathrm{O}_{2}, \mathrm{Ar}$, and $\mathrm{CO}_{2}$. These data will contribute to studies of thermosphere energetics, lower atmosphere dust storms, the formation of the ionosphere and the interaction of the upper atmosphere with the solar wind.

Acknowledgments. M. Kimura of the Planet-B orbit design group supplied the most recent orbit parameters for the main phase of the Planet-B mission. C. Acton, B. Taber, and B. Semenov of the Jet Propulsion Laboratory, Navigation Ancillary Information Facility, provided the SPICE kernel and programming help to perform the orbit calculations. The effort is appreciated.

\section{References}

Bougher, S. W. and H. Shinagawa, The Mars thermosphere-ionosphere: Predictions for the arrival of Planet-B, Earth Planets Space, 50, 247257, 1998.

Bougher, S. W., R. G. Roble, E. C. Ridley, and R. E. Dickinson, The Mars thermosphere 2 . General circulation with coupled dynamics and composition, J. Geophys. Res., 95, 14811-14827, 1990.

Bougher, S. W., J. R. Murphy, and R. M. Haberle, Dust storm impacts on the Mars upper atmosphere, Adv. Space Res., 19(8), 1255-1260, 1997.

Grebowsky, J. M., W. T. Kasprzak, R. E. Hartle, and T. M. Donahue, A new look at Venus' thermosphere $\mathrm{H}$ distribution, Adv. Space Res., 17, (11)191-(11)195, 1995.

Hanson, W. B., S. Sanatani, and D. R. Zuccaro, The Martian ionosphere as observed by the Viking retarding potential analyzers, J. Geophys. Res., 82, 4351-4363, 1977.

Hunten, D. M., Atmospheric evolution of the terrestrial planets, Science, 259, 915-920, 1993.

Joselyn, J. A., J. B. Anderson, H. Coffey, K. Harvey, D. Hathaway, G. Heckman, E. Hildner, W. Mende, K. Schatten, R. Thompson, A. W. P. Thomson, and O. R. White, Panel achieves consensus prediction of solar cycle 23, EOS Transactions AGU, 78(20), 205, 211-212, 1997.

Kasprzak, W. T., A. E. Hedin, H. B. Niemann, and N. W. Spencer, Atomic nitrogen in the upper atmosphere of Venus, Geophys. Res. Lett., 7, 106$108,1980$.

Kasprzak, W. T., A. E. Hedin, H. G. Mayr, and H. B. Niemann, Wavelike perturbations in the neutral thermosphere of Venus, J. Geophys. Res., 93, 11237-11245, 1988.

Kasprzak, W. T., H. B. Niemann, A. E. Hedin, and S. W. Bougher, Wavelike perturbations observed at low altitudes by the Pioneer Venus orbiter neutral mass spectrometer during orbiter entry, Geophys. Res. Lett., 20, 2755-2758, 1993a.

Kasprzak, W. T., H. B. Niemann, A. E. Hedin, S. W. Bougher, and D. M. Hunten, Neutral composition measurements by the Pioneer Venus neutral mass spectrometer during re-entry, Geophys. Res. Lett., 20, 2747-2750, $1993 b$.

Krasnopolsky, V. A., S. Bowyer, S. Chakrabarti, G. R. Gladstone, and J. S. McDonald, First measurement of helium on Mars: Implications for the problem of radiogenic gases on the terrestrial planets, Icarus, 109, 337-351, 1994.

Luhmann, J. G., W. T. Kasprzak, and J. M. Grebowsky, On removing molecular ions from Venus, J. Geophys. Res., 100, 14515-14521, 1995.

Lundin, R., A. Zakharov, R. Pellinen, H. Borg, B. Hultqvist, N. Pissarenko, E. M. Dubinin, S. W. Barabasj, I. Liede, and H. Koskinen, First measurements of the ionospheric plasma escape from Mars, Nature, 341, 609-612, 1989.

Mayr, H. G., I. Harris, H. B. Niemann, H. C. Brinton, N. W. Spencer, H. A. Taylor, Jr., R. E. Hartle, and W. R. Hoegy, Dynamic properties of the thermosphere inferred from Pioneer Venus mass spectrometer measurements, J. Geophys. Res., 85, 7841-7847, 1980.

Nagy, A. F., J. Kim, and T. E. Cravens, Hot hydrogen and oxygen atoms in the upper atmospheres of Venus and Mars, Ann. Geophys., 8, 251-256, 1990.

Niemann, H. B., J. R. Booth, J. E. Cooley, R. E. Hartle, W. T. Kasprzak, N. W. Spencer, S. H. Way, D. M. Hunten, and G. R. Carignan, Pioneer Venus orbiter neutral gas mass spectrometer experiment, IEEE Trans. Geosci. Remote Sensing, GE-18, No. 1, 60-65, 1980a.

Niemann, H. B., W. T. Kasprzak, A. E. Hedin, D. M. Hunten, and N. W. Spencer, Mass spectrometric measurements of the neutral gas composition of the thermosphere and exosphere of Venus, J. Geophys. Res., 85, 7817-7827, 1980b.

Nier, A. O. and M. B. McElroy, Composition and structure of Mars' upper atmosphere: Results from the neutral mass spectrometers on Viking 1 and 2, J. Geophys. Res., 82, 4341-4349, 1977. 
Planet-B Interim Report, SES-TD-94-022, Institute of Space and Astronautical Science, SES Data Center, February, 1995.

Rodrigo, R., E. Garcia-Alvarez, M. J. Lopez-Gonzalez, and J. J. LopezMoreno, A non-steady one-dimensional theoretical model of Mars' neutral atmospheric composition between 30 and $200 \mathrm{~km}$, J. Geophys. Res., 95, 14795-14810, 1990.

Schatten, K. H. and W. D. Pesnell, An early solar dynamo prediction: cycle $23 \sim$ cycle 22, Geophys. Res. Lett., 20, 2275-2278, 1993.

Stewart, A. I., Mariner 6 and 7 ultraviolet spectrometer experiment: Impli- cations of $\mathrm{CO}_{2}^{+}, \mathrm{CO}$, and $\mathrm{O}$ airglow, J. Geophys. Res., 77, 54-68, 1972.

H. B. Niemann (e-mail: Hasso.B.Niemann@gsfc.nasa.gov), D. N. Harpold, S. Feng, W. T. Kasprzak, S. H. Way, S. K. Atreya, B. Block, G. R. Carignan, T. M. Donahue, A. F. Nagy, S. W. Bougher, D. M. Hunten, T. C. Owen, S. J. Bauer, H. J. Hayakawa, T. Mukai, Y. N. Miura, and N. Sugiura 